\title{
Effect of Patient Transfer Training on Low Back Pain in Pre-hospital Emergency Medical Services Personnel
}

\author{
Kiomars Yahyaei $^{1}$, Khadijeh Yazdi*2, Shohreh Kolagari² ${ }^{2}$, Hosein Rahmani ${ }^{3}$
}

1. School of Nursing and Midwifery, Golestan University of Medical Sciences, Gorgan, Iran.

Orcid.org/0000-0002-6983-2871

2. Nursing Research Center, Golestan University of Medical Sciences, Gorgan, Iran. Orcid.org/0000-00024311-1419.

2. Shohreh Kolagari. Nursing Research Center, Golestan University of Medical Sciences, Gorgan, Iran.

Orcid.org/0000-0001-6544-5383

3. Department of Medical-Surgical Nursing, School of Nursing and Midwifery, Golestan University of

Medical Sciences, Gorgan, Iran. Orcid.org/ 0000-0002-8475-5843

\begin{abstract}
Background and objectives: Pre-hospital emergency medical services (EMS) personnel are responsible for transferring patients. In case of improper patient handling, these individuals become vulnerable to various musculoskeletal problems including back pain. In this study, we aimed to evaluate the impact of an eight-hour training intervention about patient handling and transfer ergonomics on low back pain in pre-hospital EMS personnel working in the Golestan Province,
\end{abstract} Iran.

Methods: This was a quasi-experimental study with a pre-test/post-test design. The study population consisted of 200 pre-hospital EMS personnel working in the Golestan Province, Iran. Overall, 40 EMS personnel were eligible to participate in the study. Data were collected using a demographic questionnaire, the Oswestry low back pain disability questionnaire and the Quebec back pain disability scale. The eight-hour training session was held by a research nurse, a physiotherapist and a physician. The subjects recompleted the Oswestry low back pain disability questionnaire and the Quebec back pain disability scale at baseline, four weeks and 12 weeks postintervention. The collected data were analyzed using SPSS 16 and descriptive statistics.

Results: The mean age, body mass index and work experience was $38.6 \pm 7.6$ years, $25.9 \pm 3.5$ $\mathrm{kg} / \mathrm{m}^{2}$ and $8.27 \pm 5.2$ years, respectively. The mean score of functional disability reduced significantly from $35.9 \pm 9$ at baseline to $27.5 \pm 2.5$ and $19.6 \pm 7$ four weeks and 12 weeks after the intervention, respectively $(\mathrm{P}=0.0001)$. Furthermore, the mean pain score decreased from $38.7 \pm$ 13.86 to $31.05 \pm 10.75$ one month post-intervention and to $22.4 \pm 9.47$ three months postintervention $(\mathrm{P}=0.0001)$.

Conclusion: Our findings suggest that training intervention on ergonomic patient transfer and patient handling can reduce the rate of lower back pain in pre-hospital EMS personnel.

Keywords: Education; Patient transfer; Low Back Pain; Pre-hospital Emergency

\section{Received: 2019/11/30 $\quad$ Revised:2019/12/15}

Published:2019/12/30

*Correspondence: Khadijeh Yazdi, Nursing Research Center, Golestan University of Medical Sciences,

Gorgan, Iran

Tel: +989111752641

Email: yazdi@goums.ac.ir

Email: mehravar10261@yahoo.com 


\section{INTRODUCTION}

Nurses and paramedical staff, especially prehospital emergency medical services (EMS) personnel, are at high risk of low back pain (1-4). According to a systematic review and meta-analysis, the prevalence of low back pain in emergency settings was $4.39 \%$ between 2000 and 2016, with the prevalence ranging from 0.9 to $17.1 \%$ among different countries (5). In Iran, the prevalence of back pain among nurses was reported between 70 to $78 \%$ in different cities, but the overall prevalence of this problem is not clear $(4,6-$ 9).

Back pain is associated with some individual and occupational factors (10) that may be due to the nature of pre-hospital EMS, such as exposure to stressful conditions and work environment, intense physical activity and prolonged standing (1-3). In fact, low back pain is a multidimensional problem that affects the performance and quality of life of pre-hospital EMS personnel (4) and leads to depression, anxiety and decreased job satisfaction (11). This problem is also a common cause of long-term sick leave and early retirement (12). Therefore, ergonomics training along with workplace assessment, rehabilitation and stress management strategies are essential in these personnel (4). Previous studies have also shown the effectiveness of ergonomic interventions such as dynamics-based training programs, training on prevention of work-related musculoskeletal disorders, proper patient transfer techniques and exercises that could prevent low back pain (13-15). According to a systematic review, pre-post studies are the most suitable for assessing the effect of patient transfer interventions (13). Therefore, this study aimed to determine the effect of proper ergonomic patient transfer practice on low back pain in pre-hospital EMS personnel.

\section{MATERIALS AND METHODS}

The present study is a quasi-experimental study with a pre-test/post-test design. The study population consisted of 200 pre-hospital EMS personnel working in the Golestan Province, Iran. Inclusion criteria included a score of 25 and above on the Oswestry disability index and the Quebec back pain disability scale, working in the emergency department and being in charge of patient transfers. Those with a second job and history of depression, underlying illness and regular exercise were excluded from the study. Overall, 40 EMS personnel were included in the study.

Data were collected using a demographic questionnaire, the Oswestry Low Back Pain Disability questionnaire and the Quebec back pain disability scale. The Oswestry Low Back Pain Disability questionnaire evaluates the functional ability of an individual with 10 items that are scored zero to five in the areas of pain tolerance, personal care, lifting, walking, sitting, standing, sleeping, social life, travel and pain intensity changes. The score of each section are multiplied by two and an overall score of zero to 100 represents the person's level of disability. Thus, a score of zero indicates good overall health and painfree performance, 0-25 means mild disability, 25-50 represents moderate disability, 50-75 shows severe disability, and 75-100 indicates complete disability (16).

The Quebec back pain disability scale consists of 25 questions that are scored zero to four and determine pain intensity (zero to $100)$ in everyday activities. In this questionnaire, score of zero indicates good overall health, a score of $0-25$ indicates mild pain, 25-50 represents moderate pain, 50-75 indicates severe pain, and score of 75-100 shows very severe and debilitating pain (17).

After signing a consent form and completing the questionnaires, all EMS personnel with a pain and disability score of 25 or above were enrolled in the study. Due to the intensive 24hour shifts, the subjects were divided into two groups. For both groups, an 8-hour training session was held by a research nurse, a physiotherapist and a physician in charge of the emergency training center in Gorgan, Golestan Province. This training session included theoretical and practical training on the correct ergonomics and movement in patient transfer and the dynamics of back pain 
prevention. Four and 12 weeks after the training sessions, the participants recompleted the Oswestry low back pain disability questionnaire and the Quebec back pain disability scale and the obtained data were compared to baseline data.

In this study, all ethical considerations were taken into account and the participants were ensured about the confidentiality of their information. In addition, the study protocol received approval from the Ethics Committee of the Golestan University of Medical Sciences (approval code: 94185).

Table 1. Frequency distribution of demographic variables in the subjects

\begin{tabular}{|c|c|c|c|}
\hline \multicolumn{2}{|c|}{ Variables } & Frequency & Percent \\
\hline \multirow{2}{*}{ Marital status } & Single & 5 & 10.4 \\
\cline { 2 - 4 } Education level & Married & 43 & 89.6 \\
\cline { 2 - 4 } & $\begin{array}{c}\text { Diploma and } \\
\text { Associate Degree }\end{array}$ & 32 & 66.7 \\
\cline { 2 - 4 } & $\begin{array}{c}\text { Undergraduate and } \\
\text { graduate }\end{array}$ & 16 & 33.3 \\
\hline $\begin{array}{c}\text { Economic } \\
\text { status }\end{array}$ & Poor and moderate & 41 & 85.4 \\
\cline { 2 - 4 } & Well and great & 7 & 14.6 \\
\hline \multicolumn{2}{|c}{ Total } & 48 & 100 \\
\hline
\end{tabular}

Based on the results from the Quebec back pain disability scale, $70 \%$ of the subjects had moderate low back pain before the intervention, which was reduced to $62.5 \%$ one month and to $30 \%$ three months after the intervention. Moreover, $20 \%$ of the subjects had severe pain before the intervention, which
All data were analyzed in SPSS 16 using descriptive statistics, the KolmogorovSmirnov test, repeated measures ANOVA and Bonferroni test. All statistical analyses were performed at significance level of 0.05 .

\section{RESULTS}

The mean age, body mass index and work experience was $38.6 \pm 7.6$ years, $25.9 \pm 3.5$ $\mathrm{kg} / \mathrm{m} 2$ and $8.27 \pm 5.2$ years, respectively. The frequency distribution of socioeconomic variables in the subjects is shown in table 1.

Table 2. Frequency of low back pain in the participants before and after the intervention

\begin{tabular}{|c|c|c|c|c|c|c|}
\hline $\begin{array}{c}\text { Pain intensity } \\
\text { score }\end{array}$ & \multicolumn{2}{|c|}{$\mathbf{0 - 2 5}$ (mild) } & \multicolumn{2}{c|}{ 25-50 (moderate) } & \multicolumn{2}{c|}{ 50-75 (severe) } \\
\hline $\begin{array}{c}\text { Before the } \\
\text { intervention }\end{array}$ & 4 & 10 & 28 & 70 & 8 & 20 \\
\hline $\begin{array}{c}\text { One month } \\
\text { after the } \\
\text { intervention }\end{array}$ & 13 & 32.5 & 25 & 62.5 & 2 & 5 \\
\hline $\begin{array}{c}\text { Three } \\
\text { months after } \\
\text { the }\end{array}$ & 27 & 67.5 & 12 & 30 & 1 & 2.5 \\
intervention
\end{tabular}


Journal of Clinical and Basic Research (JCBR). 2019; 3(4): P 31-36.

Based on the results obtained from the Oswestry low back pain disability questionnaire, $87.5 \%$ of the subjects had moderate functional disability and the rest had severe functional disability. However, one month after the intervention, none of the participants had severe functional disability, $70 \%$ had moderate functional disability and $30 \%$ had mild functional disability. Three months after the intervention, the frequency of moderate and mild functional disability was $20 \%$ and $80 \%$, respectively (Table 3 ).

Table 3. Frequency of Oswestry functional disability in subjects with low back pain

\begin{tabular}{|c|c|c|c|c|c|c|}
\hline $\begin{array}{c}\text { Functional } \\
\text { disability }\end{array}$ & \multicolumn{2}{|c|}{$0-25$ (mild) } & \multicolumn{2}{c|}{ 25-50 (moderate) } & \multicolumn{2}{c|}{$50-75$ (severe) } \\
\hline & Frequency & Percent & Frequency & Percent & Frequency & Percent \\
\hline $\begin{array}{c}\text { Before the } \\
\text { intervention }\end{array}$ & 0 & 0 & 35 & 87.5 & 5 & 12.5 \\
\hline $\begin{array}{c}\text { One month } \\
\text { after the } \\
\text { intervention }\end{array}$ & 12 & 30 & 28 & 70 & 0 & 0 \\
\hline $\begin{array}{c}\text { Three months } \\
\text { after the } \\
\text { intervention }\end{array}$ & 32 & 80 & 8 & 20 & 0 & 0 \\
\hline
\end{tabular}

According to the Oswestry Low Back Pain Disability questionnaire, the mean score of functional disability reduced significantly after the intervention (Table 4).

Table 4. Mean score of Oswestry functional disability in subjects with low back pain

\begin{tabular}{|c|c|c|c|c|c|c|c|}
\hline & \multicolumn{2}{|c|}{$\begin{array}{c}\text { Before the } \\
\text { intervention }\end{array}$} & \multicolumn{2}{c|}{$\begin{array}{c}\text { One month after the } \\
\text { intervention }\end{array}$} & \multicolumn{2}{c|}{$\begin{array}{c}\text { Three months after } \\
\text { the intervention }\end{array}$} & \multirow{2}{*}{ P-value } \\
\hline $\begin{array}{c}\text { Oswestry } \\
\text { functional } \\
\text { disability }\end{array}$ & Mean & $\begin{array}{c}\text { Standard } \\
\text { deviation }\end{array}$ & Mean & $\begin{array}{c}\text { Standard } \\
\text { deviation }\end{array}$ & Mean & $\begin{array}{c}\text { Standard } \\
\text { deviation }\end{array}$ & 0.0001 \\
\cline { 2 - 7 } & 34.07 & 8.09 & 27.47 & 5.18 & 19.67 & 6.05 & \\
\hline
\end{tabular}

\section{DISUCSSION}

The purpose of this study was to determine the effect of ergonomic patient transfer training on intensity of low back pain in prehospital EMS personnel in the Golestan Province, Iran. The findings showed that the training intervention effectively reduced the level of low back pain and its associated functional disability. Similar to our findings, in a study by Fongsri et al., a four-week, once-weekly training intervention for 80 minutes significantly reduced the mean score of low back pain, which could be due to improved patient transfer skills and improved muscle strength (19).
There is also a relationship between low back pain and poor body mechanics. In a quasiexperimental study, Owen et al. demonstrated that the rate of pain complaints and absenteeism among nurses was reduced over five years following ergonomic interventions (20). Thus, proper patient transfer techniques should be considered as a strategy to reduce back pain (21). In line with our findings, Nelson et al. reported that training on ergonomic and proper patient transfer techniques can reduce the rate of musculoskeletal disorders in nurses (22). However, Arabs et al. found no significant association between ergonomic intervention and low back pain among hospital staff (14). 
This inconsistency of results could be related to differences in the tools used for assessing pain intensity in the subjects (the Nordic musculoskeletal questionnaire vs. the Quebec back pain disability scale). According to Jouybari et al., training nurses on ergonomics and utilization of appropriate facilities can effectively improve the work environment of health care personnel (23).

\section{CONCLUSION}

Our findings suggest that training intervention on ergonomic patient transfer and patient handling can reduce the rate of low back pain in pre-hospital EMS personnel.

\section{ACKNOWLEDGEMENTS}

This article has been derived from a research project supported by the Faculty of Nursing and Midwifery at Golestan University of Medical Sciences. We would like to thank the Deputy of Research and Technology of the University for supporting this project and also the EMS personnel who participated in this project.

\section{DECLARATIONS \\ Funding}

This study was financially supported by the Golestan University of Medical Sciences, Iran.

\section{Ethics approvals and consent to participate}

Written consent was obtained from all participants. The study protocol received approval from the Ethics Committee of the Golestan University of Medical Sciences (approval code: 94185).

\section{Conflict of interest}

The authors declare that there is no conflict of interest.

\section{REFERENCES}

1. Ando S, Ono Y, Shimaoka M, Hiruta S, Hattori Y, Hori F, et al. Associations of self estimated workloads with musculoskeletal symptoms among hospital nurses. Occupational and environmental medicine. 2000;57(3):211-6.
2. Dunn KM, Croft PR. Epidemiology and natural history of low back pain. Europa medicophysica. 2004;40(1):9-13.

3. Okada N, Ishii N, Nakata M, Nakayama S. Occupational stress among Japanese emergency medical technicians: Hyogo Prefecture. Prehospital and disaster medicine. 2005;20(2):115-21. [DOI:10.1017/S1049023X00002296]

4. Adib-Hajbaghery M, Zohrehea J. Back Pain Among Paramedics: A Pilot Study. Nursing and Midwifery Studies. 2013;2(4):103-4. [DOI: 10.5812/nms.12195]

5. Edwards J, Hayden J, Asbridge M, Gregoire B, Magee K. Prevalence of low back pain in emergency settings: a systematic review and meta-analysis. BMC Musculoskeletal Disorders. 2017;18:143. [DOI:10.1186/s12891-017-1511-7]

6. Barkhordari A, Halvani G, Barkhordari M. The Prevalence of Low Back Pain among Nurses in Yazd, Southeast Iran. International Journal of Occupational Hygiene. 2015;5(1):19-21.

7. Asadi p, Monsef Kasmaei V, Zia Ziabari SM, Zohrevandi B. The prevalence of low back pain among nurses working in Poursina hospital in Rasht, Iran. Journal of Emergency Practice and Trauma. 2016;2(1):11-5.

[DOI:10.15171/jept.2015.01]

8. Abedini R, Choobineh AR, Hasanzadeh J. Musculoskeletal Disorders Related to Patient Transfer in Hospital Nursing Personnel. Health System Research Journal. 2012;8(3):385-96.

9. Faraz R, Kalroozi F, Pishgooie A, Taheriyan A, Lak M. Prevalence of spinal pain (upper and lower) and its related factors in nurses of AJA. Military Caring Sciences. 2014;1(1):36-42. [DOI:10.18869/acadpub.mcs.1.1.36]

10. Mohseni Bandpei M, Fakhri M, Ahmad Shirvani M, Bagheri Nesami M, Khalilian A. Epidemiological aspects of low back pain in nurses. Journal of Babol University Of Medical Sciences. 2005;7(2):35-40.

11. Rahimi A, Vazini H, Alhani F, Anoosheh M. Relationship Between Low Back Pain With Quality of Life, Depression, Anxiety and Stress 
Journal of Clinical and Basic Research (JCBR). 2019; 3(4): P 31-36.

Among Emergency Medical Technicians. Trauma Mon. 2015;20(2):e18686.

[DOI:10.5812/traumamon.18686]

12. Wiitavaara B, Lundman B, BarnekowBergkvist M, Brulin C. Striking a balance-health experiences of male ambulance personnel with musculoskeletal symptoms: A grounded theory. International journal of nursing studies. 2007;44(5):770-9.

[DOI:10.1016/j.ijnurstu.2006.02.007]

13. Thomas DR, Thomas YLN. Interventions to reduce injuries when transferring patients: A critical appraisal of reviews and a realist synthesis. International Journal of Nursing Studies. 2014;51(10):1381-94. [DOI:10.1016/j.ijnurstu.2014.03.007]

14. Ali Arabian F, Motamedzade M, Golmohammadi R, Moghim Beigi A, Pir Hayati F. The Impact of Ergonomics Intervention on Musculoskeletal Disorders among Nahavand Alimoradian Hospital Staff. Journal of Ergonomics. 2013;1(1):23-32.

15. Bhimani R. Prevention of Work-related Musculoskeletal Injuries in Rehabilitation Nursing. Rehabilitation nursing : the official journal of the Association of Rehabilitation Nurses. 2016;41(6):326-35.

[DOI:10.1002/rnj.185]

16. Fairbank JC, Pynsent PB. The Oswestry disability index. Spine. 2000;25(22):2940-53. [DOI:10.1097/00007632-200011150-00017]

17. Kopec JA, Esdaile JM, Abrahamowicz M, Abenhaim L, Wood-Dauphinee S, Lamping DL, et al. The Quebec Back Pain Disability Scale: Measurement Properties. Spine. 1995;20(3):34152. [DOI:10.1097/00007632-199502000-00016]

18. Mousavi SJ, Parnianpour M, Mehdian H, Montazeri A, Mobini B. The Oswestry Disability Index, the Roland-Morris Disability Questionnaire, and the Quebec Back Pain Disability Scale: translation and validation studies of the Iranian versions. Spine (Phila $\mathrm{Pa}$ 1976). 2006;31(14):E454-9.

[DOI:10.1097/01.brs.0000222141.61424.f7]

19. Fongsri U, Rawiworrakul T, Kaewboonchoo

O, Kolladarungkri T. Effects of a selfefficacy promoting program for low back pain prevention in patient transfer workers, at a university hospital in Bangkok. Asia J Public Health. 2011;2(2):4753.

20. Owen BD, Keene K, Olson S. An ergonomic approach to reducing back/shoulder stress in hospital nursing personnel: a five year follow up. International journal of nursing studies. 2002;39(3):295-302. [DOI:10.1016/S00207489(01)00023-2]

21. Bing Yip Y. A study of work stress, patient handling activities and the risk of low back pain among nurses in Hong Kong. Journal of advanced nursing. 2001;36(6):794-804. [DOI:10.1046/j.1365-2648.2001.02037.x]

22. Nelson A, Matz M, Chen F, Siddharthan K, Lloyd J, Fragala G. Development and evaluation of a multifaceted ergonomics program to prevent injuries associated with patient handling tasks. International Journal of Nursing Studies. 2006;43(6):717-33.

[DOI:10.1016/j.ijnurstu.2005.09.004]

23. Juibari L, Sanagu A, Farrokhi N. The relationship between knowledge of ergonomic science and the occupational health among nursing staff affiliated to Golestan University of Medical Sciences. Iranian Journal of Nursing and Midwifery Research. 2010;15(4):185-9. 